This document is the accepted manuscript version of the following article:

H. F. Grützmacher, J. Wang, G. Siqueira, G. Müller, D. Rentsch, A. Huch, P. Tingaut, J. LevaloisGrützmacher (2016). Synthesis of new bis(acyl)phosphane oxide photoinitiators for the surface functionalization of cellulose nanocrystals Chemical Communications. http://doi.org/10.1039/ C5CC09760F

\title{
Synthesis of new bis(acyl)phosphane oxide photoinitiators for the surface functionalization of cellulose nanocrystals ${ }^{\dagger}$
}

Jieping Wang, ${ }^{a}$ Gilberto Siqueira, ${ }^{\mathrm{b}}$ Georgina Müller, ${ }^{\mathrm{a}}$ Daniel Rentsch, ${ }^{\mathrm{b}}$ Anja Huch, ${ }^{\mathrm{b}}$ Philippe Tingaut, $^{* \text { bd }}{ }^{\text {Joëlle Levalois-Grützmacher }}{ }^{a}$ and Hansjörg Grützmacher*ac

A new synthesis of bis(acyl)phosphane oxide (BAPO) photoinitiators was developed which can be used to functionalize cellulose nanocrystals surfaces for polymer grafting. Hybrid materials with excellent graft yields can be rapidly obtained under mild and acid-free conditions.

Bis(acyl)phosphane oxides $\left(\mathrm{R}^{1} \mathrm{PO}\left(\mathrm{COR}^{2}\right)_{2} ; \mathrm{BAPOs}\right)$ are widely used as photoinitiators (PIs) to initiate radical polymerizations and found industrial applications in the preparation of pigmented and clear coatings, adhesives, inks, photo-resists, printing plates, and dental restoring materials. ${ }^{1}$ Cellulose nanocrystals (CNC) have recently attracted much attention because of their excellent mechanical properties, biodegradability, and renewability. ${ }^{2}$ However, the inherent hydrophilicity and self-aggregation upon drying often limit their applications. ${ }^{3}$ Such obstacles can be overcome by surface graft polymerization. ${ }^{4}$ Free radical polymerization (radicals are generated by various methods from an initiator in the presence of cellulose and monomer) ${ }^{5-7}$, controlled radical polymerization [atom transfer radical polymerization (ATRP) or reversible addition-fragmentation chain transfer polymerization $\left(\mathrm{RAFT}^{9}\right)^{9}$, and ring opening polymerization ${ }^{10}$ (cellulose surface hydroxyl groups act as initiating sites) were used for this purpose. Free radical polymerization is able to polymerize a wide range of monomers in a short time and is tolerant to water or other impurities, but rather harsh conditions are required to generate radicals in most cases.

To the best of our knowledge, few photoinitiators have been used to modify cellulose surfaces. ${ }^{11}$ Here, we present a

\footnotetext{
aepartment of Chemistry and Applied Biosciences, ETH Zürich, 8093 Zürich, Switzerland. E-mail: hgruetzmacher@ethz.ch.

b. EMPA, Swiss Federal Laboratories for Materials Science and Technology, 8600 Dübendorf, Switzerland. E-mail: philippe.tingaut@gmail.com.

Lehn Institute of Functional Materials (LIFM), Sun Yat-Sen University, 510275

Guangzhou, China.

d. Present address: SOCOMORE / ZI du Prat - CS 23707, 56037 VANNES Cedex, Fra

nce.

tElectronic Supplementary Information (ESI) available: Experimental details including materials, sample preparation, and WXRD, FT-IR, ${ }^{13} \mathrm{C}$ and ${ }^{31} \mathrm{P} C \mathrm{CP}-\mathrm{MAS}$ NMR, DSC and TGA characterization.
}

new and straightforward synthesis of highly photoactive BAPO derivatives and the use of this reaction for a simple and highly reliable modification of CNC surfaces under mild conditions. ${ }^{12}$

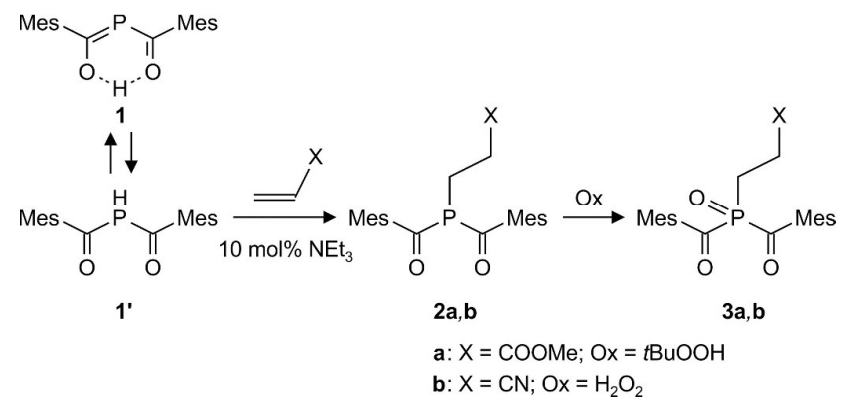

Scheme 1 Synthesis of BAPO derivatives via Phospha-Michael addition. EWG $=$ electron withdrawing group, Mes = mesityl.

Bis(mesitoyl)phosphane (1) is easily accessible and an airstable crystalline yellow substance which in solution exists in an equilibrium between tautomers 1 and $\mathbf{1}^{\prime} .{ }^{13}$ We found that, in the presence of catalytic amounts of amine (10 mol\%), 1 reacted readily with activated olefins like methyl acrylate or acrylonitrile in a Phospha-Michael addition (Scheme 1). ${ }^{14}$ The resulting bis(mesitoyl)phosphanes were characterized by ${ }^{31} \mathrm{P}$ NMR, exhibiting resonances at $49.9 \mathrm{ppm}$ (2a) and $50.5 \mathrm{ppm}$ (2b), respectively. Subsequently, the corresponding bis(acyl)phosphane oxides $\mathbf{3 a}$ and $\mathbf{3 b}$ were obtained in high yields after oxidation with either $t \mathrm{BuOOH}$ (3a) or aqueous $\mathrm{H}_{2} \mathrm{O}_{2}$ (3b). In the ${ }^{31} \mathrm{P}$ NMR spectra, signals at $26.5 \mathrm{ppm}$ (3a) and 23.3 ppm (3b) were observed. While $\mathbf{3 a}$ is a viscous oil, compound $\mathbf{3 b}$ is crystalline (for a single crystal structure analysis of $\mathbf{3 b}$, see Fig. S1, ESI+). 

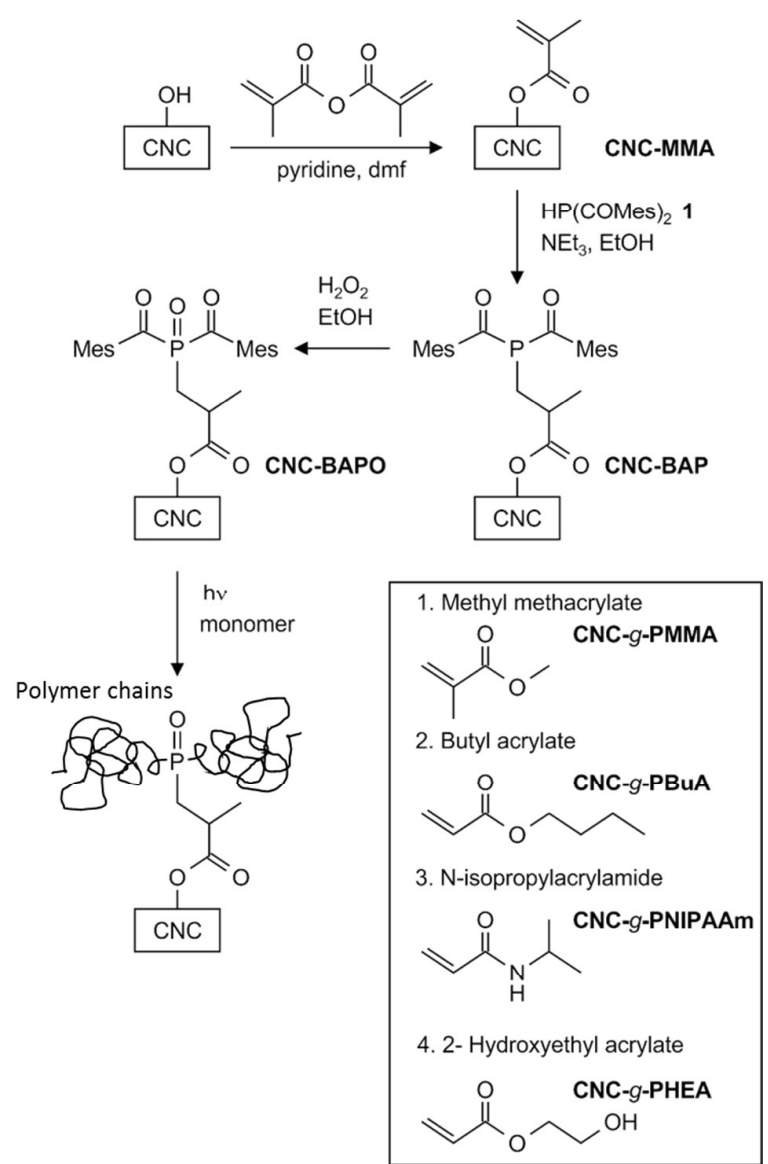

Scheme 2 Functionalization of cellulose nanocrystals with a BAPO photoinitiator and the following polymerization.

In order to functionalize CNC (derived from wood pulp by sulfuric acid treatment, provided by the University of Maine), methacryloyl groups were attached to their surfaces as shown in Scheme 2. To these, $\mathrm{HP}(\mathrm{COMes})_{2}(\mathbf{1})$ was added to give CNCBAP and subsequent oxidation with aqueous $\mathrm{H}_{2} \mathrm{O}_{2}$ generated quantitatively CNC-BAPO. Elemental analysis of the final yellow powder indicates a phosphorus content of $1.0 \%$ which corresponds to $0.33 \mathrm{mmol}$ bis(acyl)phosphane oxide (BAPO) per gram of CNC.

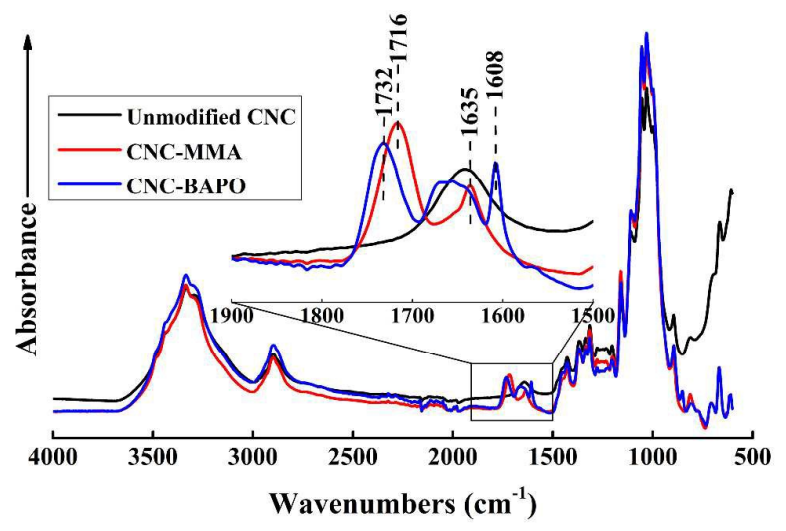

Fig. 1 FT-IR spectra of unmodified CNC, CNC-MMA and CNC-BAPO.
The successful immobilization was confirmed by Fourier transform infrared spectroscopy (FT-IR), see Fig. 1. The peaks at $1716 \mathrm{~cm}^{-1}$ and $1635 \mathrm{~cm}^{-1}$ in the CNC-MMA sample are attributed to the stretching vibration of the carbonyl $\left(v_{\mathrm{C}=0}\right)$ and alkene groups $\left(\mathrm{v}_{\mathrm{C}=\mathrm{c}}\right)$, respectively. After the addition of BAPO, a new absorption at $1608 \mathrm{~cm}^{-1}$ is observed which is assigned to the stretching vibration of the $\mathrm{C}=\mathrm{C}$ bonds in the mesityl (Mes) ring while $\mathrm{v}_{\mathrm{C}=\mathrm{O}}$ is shifted to a higher wavenumber at $1732 \mathrm{~cm}^{-1}$.

The presence of BAPO was further proved by ${ }^{13} \mathrm{C}$ and ${ }^{31} \mathrm{P} \mathrm{CP}$ MAS NMR spectroscopy (Fig. 2). A single signal at $23.7 \mathrm{ppm}$ in ${ }^{31} \mathrm{P}$ CP-MAS NMR spectrum of CNC-BAPO is similar to the chemical shift of $\mathbf{3 a}$ and $\mathbf{3 b}$. Typical ${ }^{13} \mathrm{C}$ signals of cellulose nanocrystals at $\delta=105.0\left(C_{1}\right), 88.6\left(C_{4}\right.$ crystalline $), 83.8\left(C_{4}\right.$ amorphous), $74.7 / 72.4\left(C_{2,3,5}\right), 65.0$ ( $C_{6}$ crystalline), and 62.9 $\operatorname{ppm}\left(\mathrm{C}_{6}\right.$ amorphous) are observed in all spectra. ${ }^{15}$ In the CNCBAPO sample, the characteristic signals of the BAPO unit at $\delta=$ 216.4 (COMes), 141.4 ( $C^{4}$ Mes), 136.1 ( $C^{2,6}$ Mes), 129.4 ( $C^{3,5}$ Mes), and $20.0\left(o, p-\mathrm{CH}_{3} \mathrm{Mes}\right)$ are clearly observed, which are absent in the spectrum of CNC-MMA. The ${ }^{13} \mathrm{C}$ signal of the $\mathrm{C}=\mathrm{O}$ group from methacrylate unit is shifted from 168.1 to 174.7 ppm, due to the addition of the BAPO group.

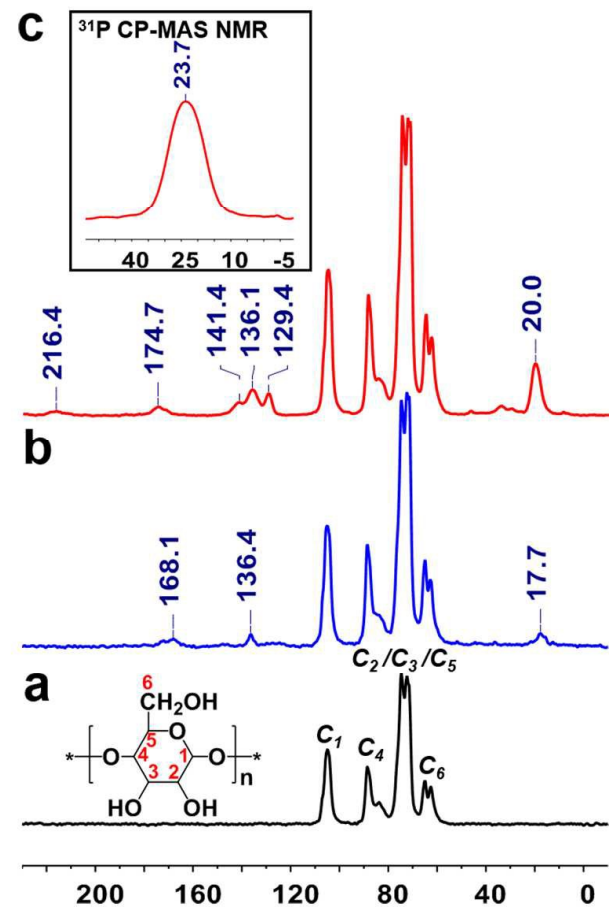

Fig. $2{ }^{13} \mathrm{C}$ CP-MAS NMR spectra of: (a) unmodified CNC, (b) CNC-MMA, (c) ${ }^{13} \mathrm{C}$ and ${ }^{31} \mathrm{P}$ CP-MAS NMR spectra of CNC-BAPO.

The TEM images in Fig. 3 show that the morphology of the CNC was maintained during the modification procedure with BAPO units. The unmodified nanocrystals exhibit an average diameter of 5-10 nm and lengths of $100-150 \mathrm{~nm}$. The BAPO functionalized nanocrystals are less individualized. This aggregation may be due to a decrease of sulfate groups or activation of the surface BAPO groups under the conditions of the TEM experiment (Table S1, ESI + ). The X-ray diffraction patterns of unmodified CNC, methacrylate, and BAPO modified CNC show that all three samples have similar crystallinity and 
exhibit patterns typical of the native crystalline form of cellulose $1 \beta$ (Fig. S2, ESI + ). Similar crystallinity indices (CI) around $72 \%$ were determined for unmodified CNC, CNC-MMA and CNC-BAPO, respectively. This suggests that the modification is limited to the surfaces of CNC.
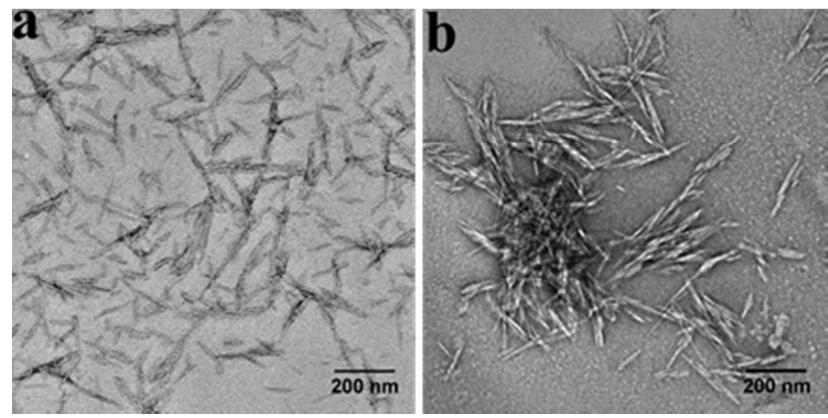

Fig. 3 Transmission electron micrographs of unmodified CNC (a), and CNC-BAPO (b).

CNC-BAPO was used to polymerize acrylic monomers under UV light irradiation (the dimension of CNC was preserved after UV irradiation, Fig. S3) at room temperature for 1 hour. The monomers used include methyl methacrylate (MMA), butyl acrylate (BuA), $N$-isopropylacrylamide (NIPAAm) and 2hydroxyethyl acrylate (HEA). Graft yield $(G)$, graft efficiency $\left(G_{E}\right)$ and elemental analysis of the polymer graft CNC are recorded in Table S1, ESIt.

High graft yields (after removing the homopolymers by Soxhlet extraction) were obtained for all tested monomers. The highest mass gain of up to $477 \%$ was achieved with MMA. BuA and NIPAAm both formed grafted polymers with masses three times greater than that of the starting CNC. HEA was less prone to graft, but the mass still increased by $200 \%$. Elemental analysis was performed to quantify the composition of the grafted materials. The mass gain calculated according to phosphorus content correlates well with the gravimetric value. Homopolymers, generated by cleaved acyl radicals, were formed in smaller amounts which confirms that phosphinoyl radicals are more reactive than acyl radicals. ${ }^{16}$

The obtained samples were characterized by FT-IR (Fig. S4, $\mathrm{ESI}+$ ). Intense absorption bands attributed to the $\mathrm{v}_{\mathrm{C}=\mathrm{O}}$ of the carboxyl groups of the grafted polymers were observed in all spectra. The bending vibration of the $\mathrm{N}-\mathrm{H}$ bond was detected at $1531 \mathrm{~cm}^{-1}$ in the CNC-g-PNIPAAm sample. Moreover, the intensities of the $\mathrm{O}-\mathrm{H}$ stretching bands of cellulose backbones at $3300 \mathrm{~cm}^{-1}$ decreased significantly in PMMA and PBuA grafted samples. This is likely caused by the grafting of the polymers from the CNC surfaces. ${ }^{10 a}$ In contrast, the intensities increased in the PNIPAAm and PHEA grafted samples, due to the overlapping of $\mathrm{N}-\mathrm{H}$ and $\mathrm{O}-\mathrm{H}$ groups present in the grafted polymer chains.

${ }^{13} \mathrm{C}$ CP-MAS NMR spectroscopy was used to characterize the polymer grafted CNC. In addition to the signals of cellulose, the resonances of the ${ }^{13} \mathrm{C}$ nuclei in the polymers were clearly observed, confirming the success of grafting (Fig. S5, ESIt).

The grafted polymer chains were cleaved from the CNC and independently investigated. ${ }^{1} \mathrm{H} \quad \mathrm{NMR}$ indicated that the structures were maintained except for PHEA (Fig. S6, ESI+). The molecular weight of the polymers varies with the monomer (see Table S1, ESI + ). MMA generated the longest chains, and the weight average molecular weight $\left(M_{w}\right)$ is $250 \mathrm{~kg} / \mathrm{mol}$. BuA and NIPAAm gave shorter chains with $M_{w}$ of about $17 \mathrm{~kg} / \mathrm{mol}$ and $70 \mathrm{~kg} / \mathrm{mol}$, respectively. Polymeric films of CNC- $g$-PMMA can be obtained by solvent casting. A film of about $0.1 \mathrm{~mm}$ thickness is shown to the right of Fig. 4 and is less transparent than a neat PMMA film (Fig. 4 middle).

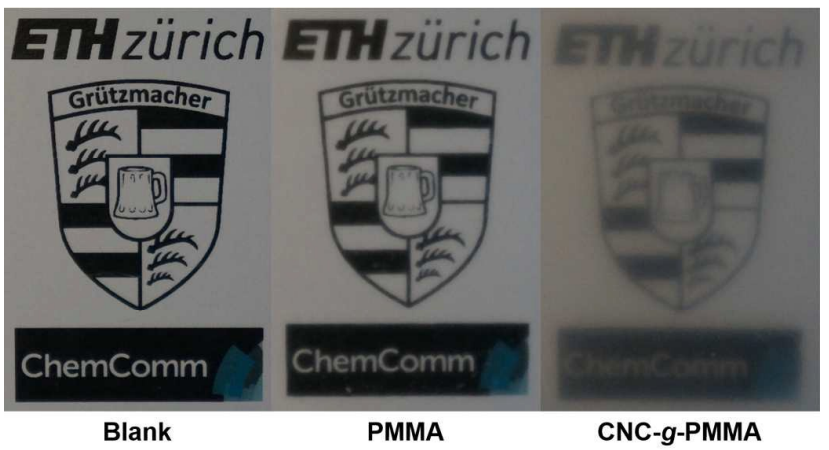

Fig. 4 Pictures of solvent casting films. Blank: background picture without film (left), with PMMA film (middle), and with CNC- $g$-PMMA film (right). Films of about $0.1 \mathrm{~mm}$ thickness were placed about $2 \mathrm{~cm}$ above the background and photographed.

DSC and TGA thermograms were recorded (Fig. S7 and S8, respectively, and Table S2, ESI + ). Glass transition temperatures $\left(T_{\mathrm{g}}\right)$ of the grafted products are slightly higher than the reported values of the homopolymers. The increase can be explained by the restriction of the mobility of grafted polymer chains to the CNC surfaces. ${ }^{17}$ In TGA thermograms, a significant increase of the onset temperature was observed for CNC grafted with PBUA, PNIPAAm and PHEA. The char yield of CNC-BAPO sample at $800{ }^{\circ} \mathrm{C}(18.3 \%)$ is much higher than the others because on cellulose substrates, organo phosphorus compounds favor char formation and suppress the concentration of combustible volatile species during thermal decomposition. ${ }^{18}$

The reinforcing properties of CNC- $g$-PMMA in a PMMA matrix were evaluated by tensile tests. The elastic modulus $(E)$, tensile strength $(\sigma)$, and elongation at break of the specimens are given in Fig. S9, ESIt. The incorporation of unmodified CNC (20 wt\%) in a PMMA matrix decreases both the elastic modulus and the tensile strength by $25 \%$ and $56 \%$, respectively. This finding can be explained by the poor compatibility between the hydrophilic CNC and the hydrophobic PMMA. The addition of CNC-g-PMMA (20 wt\%) into PMMA proved to enhance the elastic modulus by $8 \%$ without loss of the tensile strength. Elongation at break decreases significantly but the values still remain better than the composites filled with unmodified CNC.

In conclusion, a new and straightforward approach to prepare phosphorus-functionalized bis(acyl)phosphane oxides was developed, which can be used to functionalize cellulose nanocrystals for polymer grafting. Under mild and acid-free conditions, excellent graft yields were achieved. The obtained 
PMMA grafted cellulose nanocrystals show an improved mechanical performance when dispersed in a PMMA matrix. We believe that the results reported here may be developed into a reliable strategy to functionalize not only cellulose surfaces but also allow coating of other materials with polymers.

This work was financed by the Swiss National Science Foundation through the NFP 66 program, grant 136688. J.W. is grateful for financial support from the China Scholarship Council. Beatrice Fischer, Michael Wörle, Antonia Neels, Thomas Schweizer are gratefully acknowledged for the IR, DSC, TGA, WXRD and GPC measurements, respectively.

\section{Notes and references}

1 (a) K. Dietliker, A Compilation of Photoinitiator commercially available for UV today, SITA Technology Limited, Edinburgh and London, 2002; (b) J.V. Crivello, K. Dietliker and G. Bradley, Photoinitiators for Free Radical Cationic \& Anionic Photopolymerisation, Vol. III, J. Wiley \& Sons Ltd, SITA Technology Ltd, Chichester, 1998.

2 (a) Y. Habibi, L. A. Lucia and O. J. Rojas, Chem. Rev., 2010, 110, 3479; (b) D. Klemm, F. Kramer, S. Moritz, T. Lindström, M. Ankerfors, D. Gray and A. Dorris, Angew. Chem. Int. Ed., 2011, 50, 5438; (c) A. Dufresne, Materialstoday, 2013, 16, 220; (d) R. J. Moon, A. Martini, J. Nairn, J. Simonsen and J. Youngblood, Chem. Soc. Rev., 2011, 40, 3941; (e) M. Giese, L. K. Blusch, M. K. Khan and M. J. MacLachlan, Angew. Chem. Int. Ed., 2015, 54, 2888; (f) S. Eyley and W. Thielemans, Chem. Commun., 2011, 47, 4177; (g) L. J. Nielsen, S. Eyley, W. Thielemans and J. W. Aylott, Chem. Commun., 2010, 46, 8929.

3 (a) P. Tingaut, T. Zimmermann and G. Sèbe, J. Mater. Chem., 2012, 22, 20105; (b) J. P. F. Lagerwall, C. Schütz, M. Salajkova, J. H. Noh, J. H. Park, G. Scalia and L. Bergström, NPG Asia Mater., 2014, 6, e80; (c) N. Ling and A. Dufresne, Nanoscale, 2014, 6, 5384.

4 (a) S. Eyleya and W.Thielemans, Nanoscale, 2014, 6, 7764; (b) Y. Habibi, Chem. Soc. Rev., 2014, 43, 1519; (c) D. Roy, M. Semsarilar, J. T. Guthrie and S. Perrier, Chem. Soc. Rev., 2009, 38, 2046.

5 (a) L. H. C. Mattoso, E. S. Medeiros, D. A. Baker, J. Avloni, D. F. Wood and W. J. Orts, J. Nanosci. Nanotechnol., 2009, 9, 2917; (b) C. Zhou, Q. Wu, Y. Yue and Q. Zhang, J. Colloid Interface Sci., 2011, 353, 116; (c) J. Tang, M. F. X. Lee, W. Zhang, B. Zhao, R. M. Berry and K. C. Tam, Biomacromolecules, 2014, 15, 3052.

6 (a) K. Littunen, U. Hippi, L.-S. Johansson, M. Österberg, T. Tammelin, J. Laine and J. Seppälä, Carbohydr. Polym., 2011, 84, 1039; (b) P. Stenstad, M. Andresen, B. R. Tanem and P. Stenius, Cellulose, 2008, 15, 35.

7 (a) S. Margutti, S. Vicini, N. Proietti, D. Capitani, G. Conio, E. Pedemonte and A. L. Segre, Polymer, 2002, 43, 6183; (b) L. C. V. Wielen and A. J. Ragauskas, Eur. Polym. J., 2004, 40, 477; (c) V. Kumar, Y. K. Bhardwaj, S. N. Jamdar, N. K. Goel and S. Sabharwal, J. Appl. Polym. Sci., 2006, 102, 5512.

8 (a) A. Carlmark and E. Malmström, J. Am. Chem. Soc., 2002, 124, 900; (b) D. Nyström, J. Lindqvist, E. Östmark, A. Hult and E. Malmström, Chem. Commun., 2006, 34, 3594; (c) Q. Xu, J. Yi, X. Zhang and H. Zhang, Eur. Polym. J., 2008, 44, 2830.

9 (a) S. Perrier, P. Takolpuckdee, J. Westwood and D. M. Lewis, Macromolecules, 2004, 37, 2709; (b) D. Roy, J. T. Guthrie and S. Perrier, Macromolecules, 2005, 38, 10363; (c) A. Hufendiek, V. Trouillet, M. Meier and C. Barner-Kowollik, Biomacromolecules, 2014, 15, 2563.
10 (a) Y. Habibi, A.-L. Goffin, N. Schiltz, E. Duquesne, P. Dubois and A. Dufresne, J. Mater. Chem., 2008, 18, 5002; (b) G. Chen, A. Dufresne, J. Huang and P. R. Chang, Macromol. Mater. Eng., 2009, 294, 59; (c) N. Lin, G. Chen, J. Huang, A. Dufresne and P. R. Chang, J. Appl. Polym. Sci., 2009, 113, 3417; (d) M. Labet and W. Thielemans, Polym. Chem., 2012, 3, 679 .

11 (a) J. L. Garnett, L.-T. Ng and V. Viengkhou, Radiat. Phys. Chem., 1999, 56, 387; (b) K. H. Hong, N. Liu and G. Sun, Eur. Polym. J., 2009, 45, 2443; (c) M. V. Biyani, M. Jorfi, C. Weder and E. J. Foster, Polym. Chem., 2014, 5, 5716.

12 A. Huber, A. Kuschel, T. Ott, G. Santiso-Quinones, D. Stein, J. Bräuer, R. Kissner, F. Krumeich, H. Schonberg, J. LevaloisGrützmacher and H. Grützmacher, Angew. Chem. Int. Ed., 2012, 51, 4648.

13 (a) G. Becker, W. Becker, M. Schmidt, W. Schwarz and M. Westerhausen, Z. Anorg. Allg. Chem., 1991, 605, 7; (b) G. Müller, M. Zalibera, G. Gescheidt, A. Rosenthal, G. SantisoQuinones, K. Dietliker and H. Grützmacher, Macromol. Rapid Commun., 2015, 36, 553.

14 (a) D. Enders, A. Saint-Dizier, M. I. Lannou and A. Lenzen, Eur. J. Org. Chem., 2006, 1, 29; (b) H. Grützmacher, G. Müller, $A$ Process for the preparation of Acylphosphanes, EP12006822; 2012, WO 2014/053455 A1.

15 Z. Zhang, P. Tingaut, D. Rentsch, T. Zimmermann and G. Sèbe, ChemSusChem, 2015, 8, 2681.

16 (a) M. Griesser, D. Neshchadin, K. Dietliker, N. Moszner, R. Liska and G. Gescheidt, Angew. Chem. Int. Ed., 2009, 48, 9359; (b) U. Kolczak, G. Rist, K. Dietliker and J. Wirz, J. Am. Chem. Soc., 1996, 118, 6477; (c) S. Jockusch and N. J. Turro, J. Am. Chem. Soc., 1998, 120, 11773; (d) M. Zalibera, P.-N. Stébé, K. Dietliker, H. Grützmacher, M. Spichty and G. Gescheidt, Eur. J. Org. Chem., 2014, 331.

17 J. O. Zoppe, Y. Habibi, O. J. Rojas, R. A. Venditti, L.-S. Johansson, K. Efimenko, M. Osterberg and J. Laine, Biomacromolecules, 2010, 11, 2683.

18 J. Alongi, R. A. Carletto, F. Bosco, F. Carosio, A. Di Blasio, F. Cuttica, V. Antonucci, M. Giordano and G. Malucelli, Polym. Degrad. Stab., 2014, 99, 111. 